\title{
EXPERIMENTAL INVESTIGATION AND MODELLING OF FDM Process PARAMETERS FOR TENSILE STRENGTH IMPROVEMENT USING RSM METHOD
}

\author{
Kenan Muhamedagic, Ahmet Cekic \& Derzija Begic-Hajdarevic
}
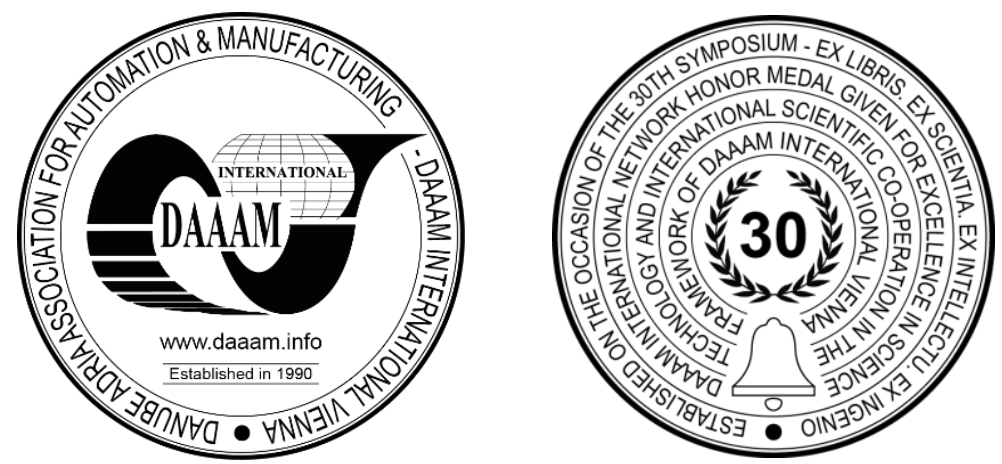

This Publication has to be referred as: Muhamedagic, K[enan]; Cekic, A[hmet] \& Begic-Hajdarevic, D[erzija] (2020). Experimental Investigation and Modelling of FDM Process Parameters for Tensile Strength Improvement Using RSM Method, Proceedings of the 31st DAAAM International Symposium, pp.0490-0498, B. Katalinic (Ed.), Published by DAAAM International, ISBN 978-3-902734-29-7, ISSN 1726-9679, Vienna, Austria

DOI: $10.2507 / 31$ st.daaam.proceedings.069

\begin{abstract}
Fused Deposition Modeling (FDM) is one of the most popular additive manufacturing technologies for various engineering applications. The FDM built part is especially anisotropic in nature due to layer-by-layer building mechanism. Therefore, the mechanical properties, especially the tensile strength severaly depend on the process parameters. Hence, the present work focuses on extensive study to understand the effect of four important parameters such as layer thickness, infill density, printing temperature and wall thickness on the tensile strength of test specimens. A total of 30 test specimens were printed using varying processing parameters according Central Composite Design of experiments (CCD) in order to reduce the experimental runs. The RSM method was used to generate a mathematical model, ie an equation (second order polynomial) which describes the process. Experimental results indicate that the wall thickness and infill density have the significant influence on tensile strength, and tensile strength increases with increasing wall thickeness and infill density. Printing temperature and layer thickness have less of an effect on tensile strength. Tensile strength increases with increasing printing temperature and decreases with increasing in layer thickness, especially at lower printing temperature.
\end{abstract}

Keywords: FDM; Tensile strength; RSM method; CCD; Process parameters.

\section{Introduction}

Additive manufacturing (AM) or 3D printing the most popular term with the public is the process of making objects by adding materials using 3D model data usually layer-by-layer [1]. AM process offers the advantage in producing parts having complex shapes with shorter production time and reduced costs as compared to traditional manufacturing process. This technology is extensively used in engineering applications for customised products, functional and prototype models. Depending on the type of materials used and the physics of the process, many AM systems are accessible in the market such Fused deposition modeling FDM, Stereolithography (SLA), Selective laser sintering (SLS), Ink jet modelling, Selective laser melting etc [2]. 
Fused deposition modeling (FDM) is one of the additive manufacturing (AM) techniques generally used to rapid prototyping, rapid tooling and fabricate direct end-use parts. FDM is capable of producing accurate and durable functional 3D parts using plastic materials such as acrylonitrile butadiene styrene (ABS), polylactic acid (PLA), poly carbonate (PC), polyethylene terephthalate (PET), thermoplastic polyurethane (TPU), Nylon, etc. In this process, the layers are formed by extrusion of a plastic filament that is unwound from a coil and supplied to the heated nozzle to produce a part. The semi-molten filament acts as a plunger to extrude the material via the nozzle (Fig 1.). The process behind this principle is that the materials are deposited in a configuration that preferably yields them layer by layer, and are hardened immediately following extrusion from the nozzle. As the process builds the part layer-by-layer, process parameters largely influence the mechanical properties, notably tensile strength of the part [3][4].

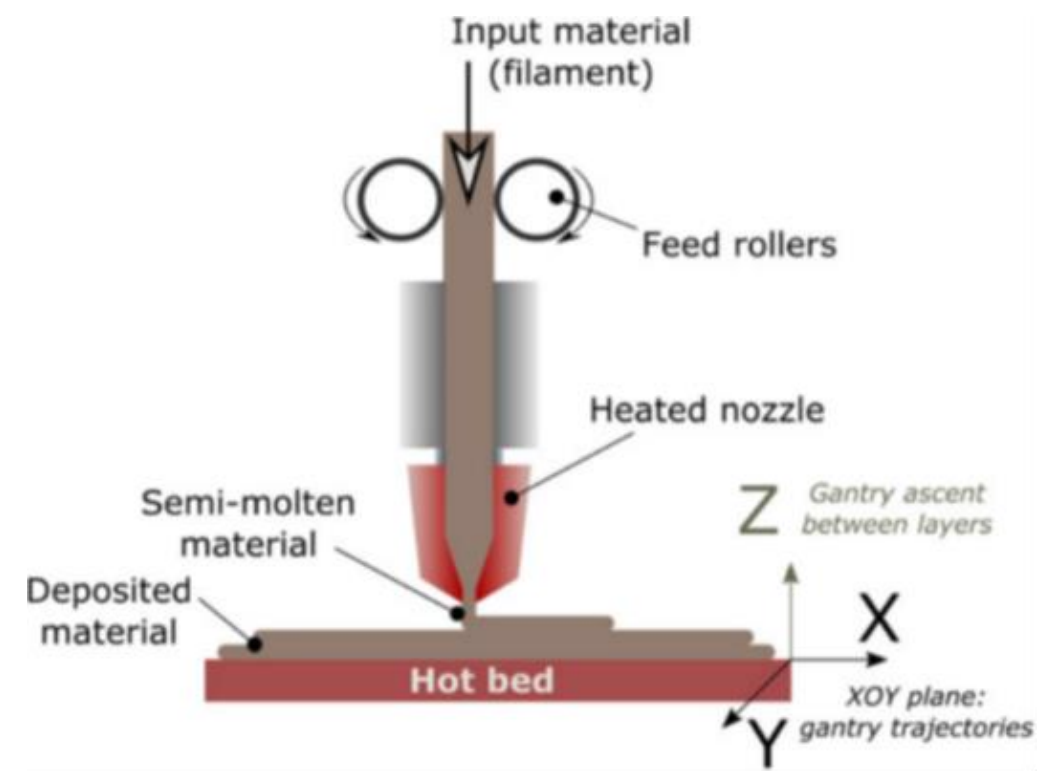

Fig. 1. Principle of FDM process [5]

The effects of layer height, build orientation, infill, countour width, printing temperature and print speed on the tensile strength of specimen built by FDM process was analyzing in many research [6][7][8]. Determination of the optimum process parameters is an important task for production engineers. It plays an important role to ensure quality of products, improve dimensional accuracy and mechanical properties, avoid unacceptable wastes and large amount of scraps, enhance productivity rates and reduce production time and cost. FDM is a complex process that exhibits much difficulty in determining optimal parameters due to the presence of a large number of conflicting parameters that will influence the part quality and mechanical properties. The part quality and mechanical properties of fabricated part can be attributed to proper selection of process parameters. Several statistical optimization techniques have been successfully used for the optimization of FDM process parameters. Based on the literature review, various optimization techniques such as the Taguchi method, ANOVA analysis, Grey relational analysis, and Response Surface Methodology were applied for optimizing FDM process parameters.

The Taguchi technique combined with Grey relational analysis is widely used by the researchers as optimization techniques. The benefits of design of experiments using the Taguchi technique includes the simplification of the experiment plan by reducing process parameters that need to be tested and feasibility to study interaction effects among different parameters [9][10]. RSM is a combination of statistical and mathematical techniques to determine the optimum operating conditions by comprehending the impact of process parameters on the output part quality [11]. The RSM technique is the most promising and powerful optimization method as it offers very low standard of error and has the ability to optimize many responses which is useful in optimizing FDM process parameters [12][13].

From literature review, it is can be seen that the process parameters have a direct impact on mechanical properties, especially the tensile strength of FDM parts. The objective of this paper is to assess the impact of four important process parameters, such as layer thickness, infill density, printing temperature and wall thickness on the tensile strength of the FDM parts. Also, a mathematical model for predicting tensile strength has been developed by using Response Surface Methodology (RSM).

\section{Experimental procedure}

For this research it used PLA (PolyLactic Acid) material from manufacturer "3D Republika" and diameter of filament wire is $2,85 \mathrm{~mm}$ for Ultimaker S3 3D printer. It is biodegradable material and is derived from renewable resources like corn starch or sugar cane. The basic properties of PLA materials from manufacturer "3D Republika" are given in Table 1 . 


\begin{tabular}{|c|c|c|}
\hline Material properties & Test method & Typical value \\
\hline Tensile Strength at Yield & ISO 527 & $70 \mathrm{MPa}$ \\
\hline Strain at Yield & ISO 527 & $5 \%$ \\
\hline E-Modulus & ISO 527 & $3120 \mathrm{MPa}$ \\
\hline Imact strength - Charpy method $23{ }^{\circ} \mathrm{C}$ & ISO 179 & $3,4 \mathrm{~kJ} / \mathrm{m}^{2}$ \\
\hline Printing temperature & DF & $205 \pm 10{ }^{\circ} \mathrm{C}$ \\
\hline Melting temperature & ISO 11357 & $115 \pm 35{ }^{\circ} \mathrm{C}$ \\
\hline
\end{tabular}

Table 1. PLA material properties by manufacturer

The dimensions of the specimens were determined in accordance with ISO 527-2 standard (standard test method for tensile properties of plastics) (Fig. 2a.). Specimens was designed using Solidworks software. Models of test specimens were saved in STL format which then were imported into 3D printing software Cura (Fig. 2b.).

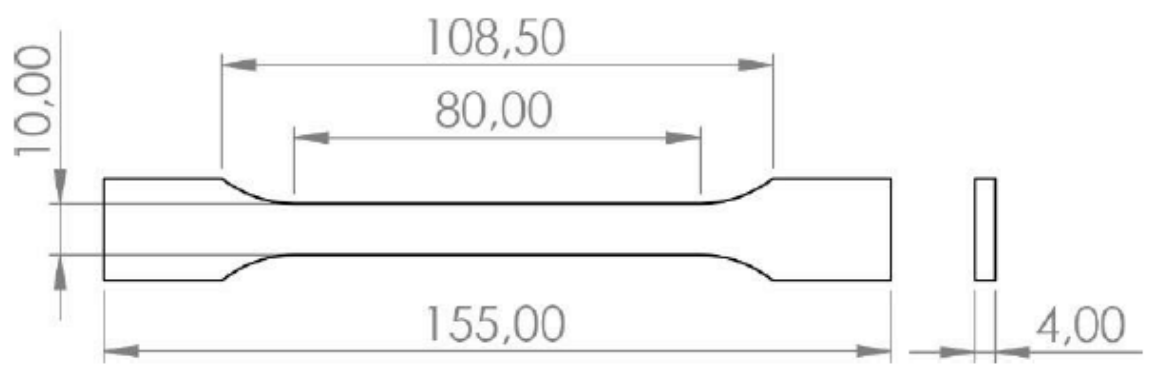

Fig. 2a. Dimensions of the specimen according to ISO 527-2

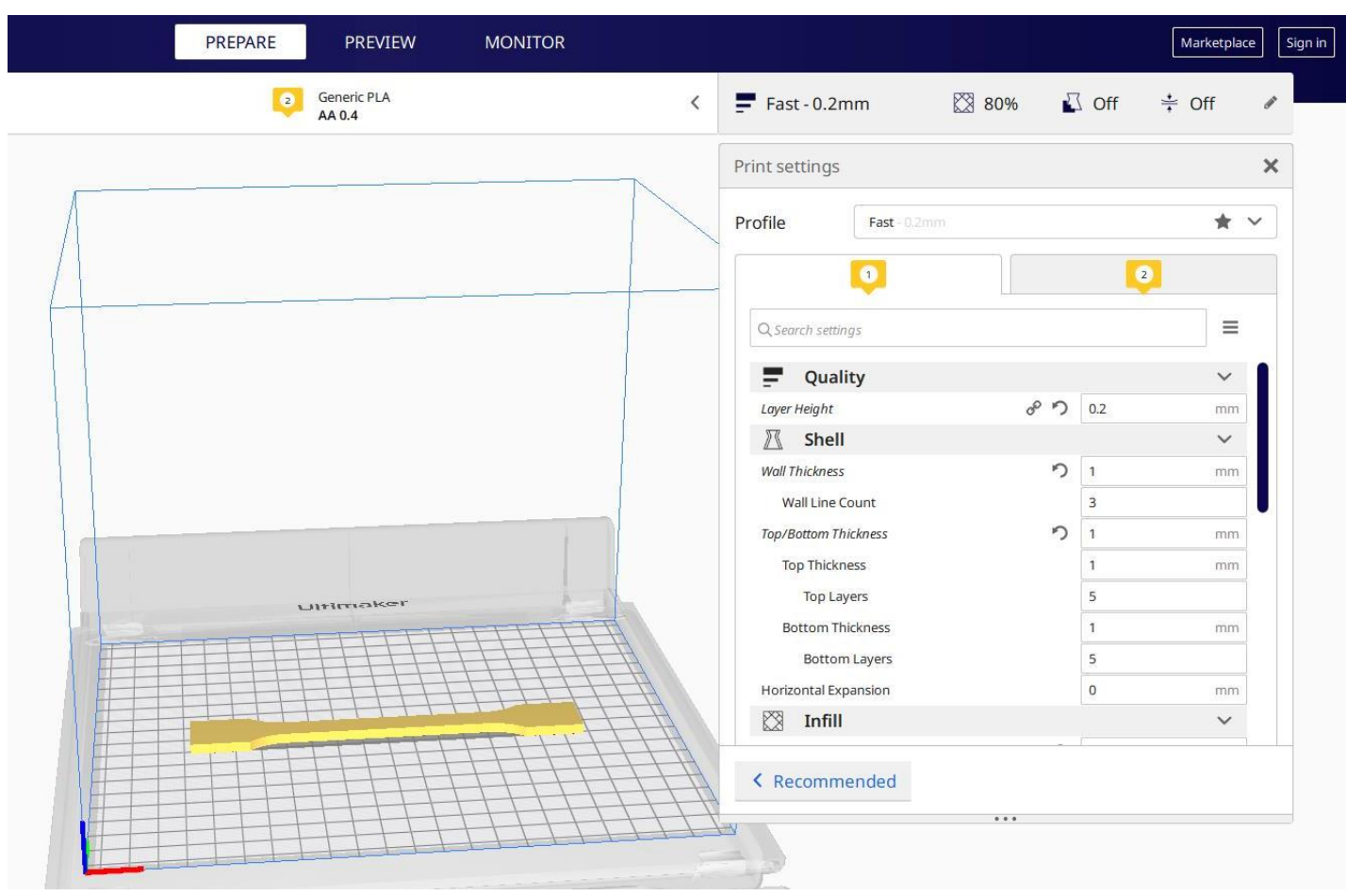

Fig. 2b. Sample preparation in slicer Cura

Regarding the software and printing configurations, the toolpath calculation (G-code) was made. The machine reads the $\mathrm{G}$ code and prints the specimen according to the instruction provided (Fig. 3.). 


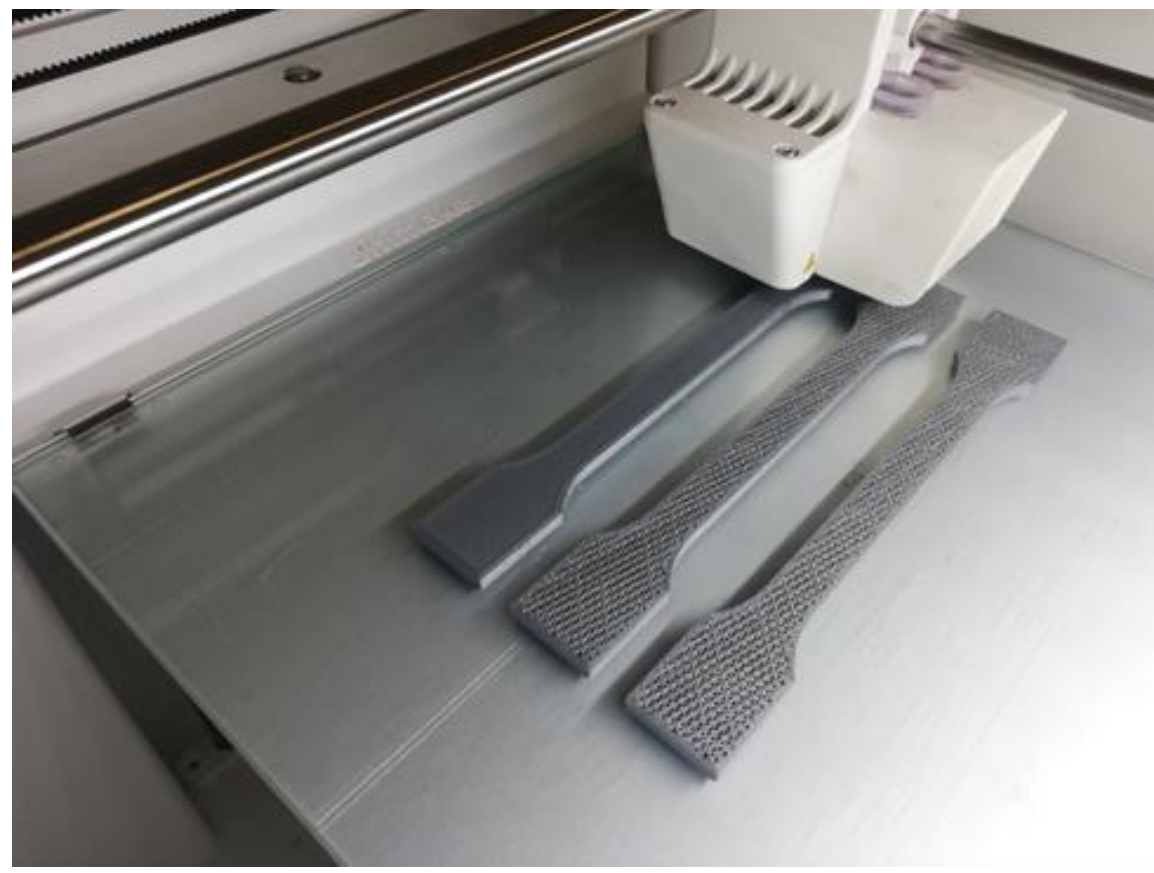

Fig. 3. 3D printing of test specimens

Tensile strength is defined as a stress, which is measured as force per unit area. Tensile strength was measured for full cross section of test specimen (also for specimens with a infill density of less than 100\%). Tests are conducted using Shimazu AGS-X automated material testing system with crosshead speed $5 \mathrm{~mm} / \mathrm{s}$ (Fig. 4.).

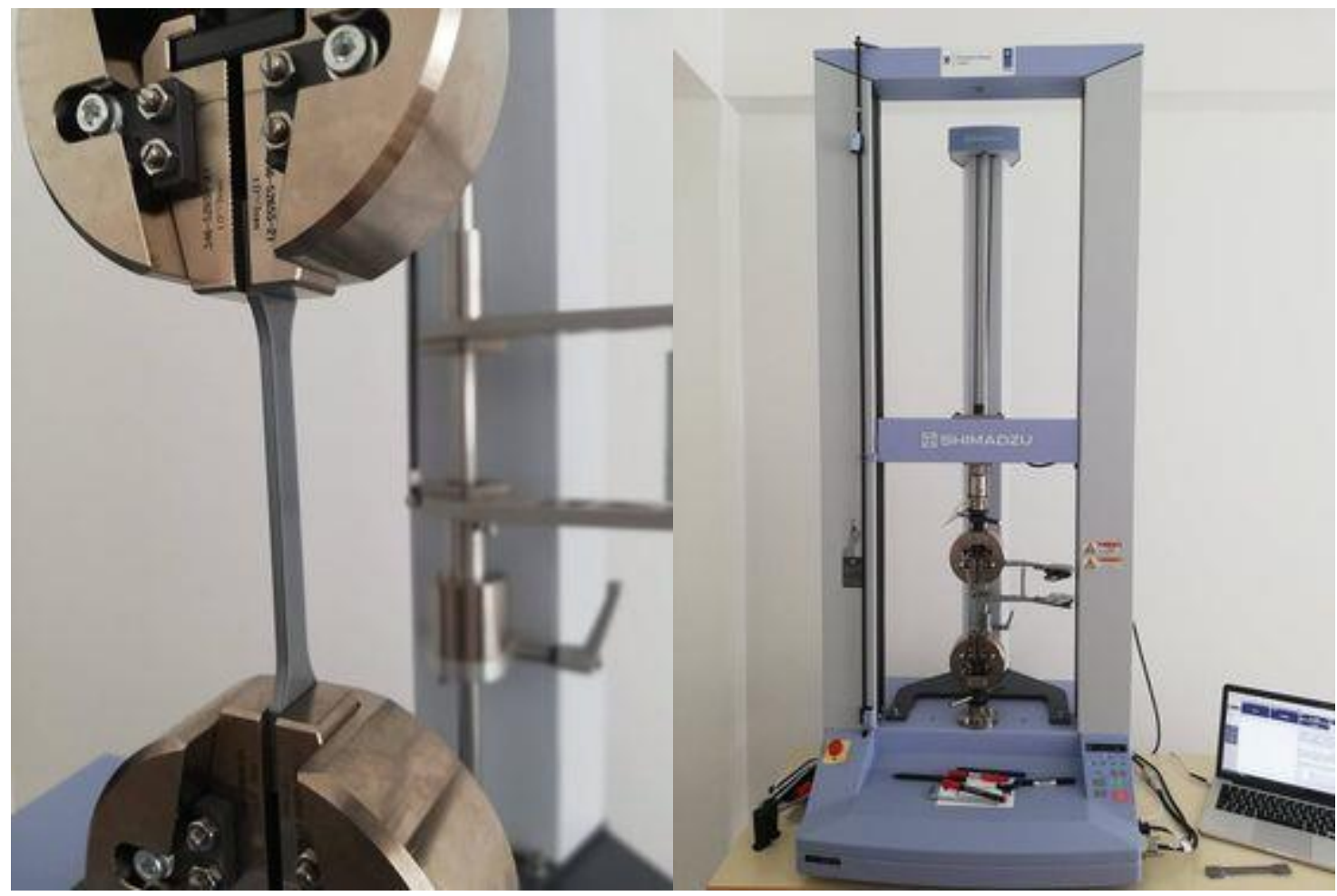

Fig. 4. Tensile testing on Shimazu AGS-X

\subsection{Design of experiment}

The mechanical strength of the FDM parts is directly affected by some process parameters. For this experimental investigations, the influence of 4 process parameters on tensile strength was analyzed. Other factors such as infill style, print speed, part orientation and build plate temperature are kept constant (Table 2.). 


\begin{tabular}{|l|l|l|}
\hline Factor & Level & Unit \\
\hline Print speed & 50 & $\mathrm{~mm} / \mathrm{s}$ \\
\hline Part orientation & 0 & degree \\
\hline Built plate temperature & 60 & ${ }^{\circ} \mathrm{C}$ \\
\hline Infill style & Triangles & - \\
\hline
\end{tabular}

Table 2. Fixed factors and their levels

Each specimen was printed under the same "flat" printing orientation $\left(0^{\circ}\right)$ shown on Fig. 3. The various process parameters are defined as:

a. Layer thickness: This is the height of the deposited layers along the Z-axis, which is generally the vertical axis of an FDM machine. Generally, it is less than the diameter of the extruder nozzle and depends on the diameter of the nozzle.

b. Infill density: he outer layers of a three-dimensional (3D) printer object are solid. However, the internal structure, commonly known as the infill, is an invisible inner part covered by the outer layer(s), and it has different shapes, sizes, and patterns. Infill density is the percentage of infill volume with filament material. The strength and mass of FDM build parts depend on the infill density.

c. Printing temperature: The temperature at which the filament of a material is heated during the FDM process. Printing temperature depends on various aspects, for example, the type of material or print speed.

d. Wall thickness: The thickness of the walls in the horizontal direction. This value divided by the wall line width defines the number of walls.

The purpose of the experiment plan is to generate a mathematical model for the mechanical strength, ie an equation (second order polynomial) which describes the influence the process parameters on tensile strength. For this experiment a Circumscribed Central Composite Design (CCCD) was used, where is for four inputs parameter $|\alpha|=2.0$. Variation of input parameters is performed on 5 levels. The zero level (centre point) is created in between high level and low level. Table 3. shows the factors along with their levels in terms of uncoded form as per CCCD, and Table 4 . shows the experimental data obtained from the CCCD runs.

\begin{tabular}{|c|c|c|c|c|c|c|c|}
\hline \multirow{2}{*}{ Factor } & \multirow{2}{*}{ Symbol } & \multirow{2}{*}{ Unit } & \multicolumn{5}{|c|}{ Levels } \\
\cline { 4 - 8 } & & & -2 & -1 & 0 & 1 & 2 \\
\hline Layer thickness & $\mathrm{A}$ & $\mathrm{mm}$ & 0,1 & 0,15 & 0,2 & 0,25 & 0,3 \\
\hline Infill density & $\mathrm{B}$ & $\%$ & 20 & 40 & 60 & 80 & 100 \\
\hline Printing temperature & $\mathrm{C}$ & ${ }^{\circ} \mathrm{C}$ & 170 & 185 & 200 & 215 & 230 \\
\hline Wall thickness & $\mathrm{D}$ & $\mathrm{mm}$ & 0,5 & 0,75 & 1 & 1,25 & 1,5 \\
\hline
\end{tabular}

Table 3. Control factors and their levels.

\begin{tabular}{|c|c|c|c|c|c|}
\hline \multirow{2}{*}{$\begin{array}{l}\text { Experiment } \\
\text { no. }\end{array}$} & \multicolumn{4}{|c|}{ Factors (coded value) } & \multirow{2}{*}{$\begin{array}{c}\text { Tensile Strength } \\
\text { (MPa) }\end{array}$} \\
\hline & A & B & $\mathrm{C}$ & D & \\
\hline 1. & 1 & -1 & -1 & -1 & 19,1 \\
\hline 2. & 1 & 1 & -1 & 1 & 30,4 \\
\hline 3. & -1 & 1 & 1 & -1 & 27,7 \\
\hline 4. & 0 & 0 & 0 & 0 & 29,2 \\
\hline 5. & 1 & -1 & 1 & 1 & 32,4 \\
\hline 6. & -1 & 1 & -1 & -1 & 26,6 \\
\hline 7. & -1 & 1 & -1 & 1 & 36,9 \\
\hline 8. & 0 & 0 & 0 & 0 & 29,3 \\
\hline
\end{tabular}




\begin{tabular}{|c|c|c|c|c|c|}
\hline 9. & 0 & 0 & 0 & 0 & 29,5 \\
\hline 10. & -1 & -1 & 1 & 1 & 36,7 \\
\hline 11. & 1 & 1 & -1 & -1 & 22,9 \\
\hline 12. & -1 & -1 & 1 & -1 & 23,8 \\
\hline 13. & 1 & 1 & 1 & -1 & 26,6 \\
\hline 14. & -1 & -1 & -1 & 1 & 34,4 \\
\hline 15. & 0 & 0 & 0 & 0 & 29,1 \\
\hline 16. & 1 & -1 & -1 & 1 & 28,3 \\
\hline 17. & -1 & 1 & 1 & 1 & 39,4 \\
\hline 18. & 1 & -1 & 1 & -1 & 29,6 \\
\hline 19. & -1 & -1 & -1 & -1 & 22,9 \\
\hline 20. & 1 & 1 & 1 & 1 & 36,1 \\
\hline 21. & 0 & 0 & 0 & 0 & 29,1 \\
\hline 22. & 0 & 0 & 0 & -2 & 19,1 \\
\hline 23. & 0 & -2 & 0 & 0 & 26,9 \\
\hline 24. & 0 & 0 & 0 & 2 & 40 \\
\hline 25. & 0 & 2 & 0 & 0 & 43,3 \\
\hline 26 & 0 & 0 & -2 & 0 & 25,7 \\
\hline 27. & 0 & 0 & 2 & 0 & 32 \\
\hline 28. & 0 & 0 & 0 & 0 & 29,9 \\
\hline 29. & -2 & 0 & 0 & 0 & 32,5 \\
\hline 30 & 2 & 0 & 0 & 0 & 29,5 \\
\hline
\end{tabular}

Table 4. Experimental runs in coded form along with the response value

\section{Results and Discussions}

Analysis of the experimental data obtained from CCCD design runs is carried out on MINITAB software. The relationship between the response and the factors are found out using the quadratic response surface model. The Response Surface Methodology (RSM) is a group statistical and mathematical methods that are useful for modeling and optimizing engineering scientific problems.

The purpose of the experiment plan is to generate a mathematical model, ie an equation (second order polynomial) which describes the process. If the factors studied in the experiment are really them which affect the process, and the data obtained by the experiment of acceptable accuracy and precision, then it is possible to develop a model that credibly describes the process. In this case, the final response surface equation in coded form is determined with $95 \%$ confidence level and given in (1).

$$
\begin{gathered}
R m=-53,1-226 A-0,002 B+0,591 C+46,8 D+64 A^{2}+0,00296 B^{2}-0,00168 C^{2}-3,23 D^{2}-0,387 A B \\
+1,433 A C-87 A D-0,001 B C+0,033 B D-0,027 C D
\end{gathered}
$$

The adequacy of the developed models was tested at $95 \%$ confidence interval by employing the ANOVA technique, which is used to test the significance of the developed model. The ANOVA results for the full quadratic models for tensile strength is shown in Table 5. From Table 5. can be seen that the probability value (P-value) for this model is smaller than 0.05 , indicating that the terms in the model have significant effect on the output responses. It confirms that the developed models have $95 \%$ confidence level. Coefficient of determination $\left(R^{2}\right)$ was found to be very close to $1\left(R^{2}=91,84 \%\right)$, indicating a high precision, good fit, and good correlation between the predicted and the experimental values. 


\begin{tabular}{|c|c|c|c|c|c|c|c|c|c|}
\hline \multicolumn{2}{|l|}{ Source } & \multirow{2}{*}{$\begin{array}{l}\text { DF } \\
14\end{array}$} & \multirow{2}{*}{$\begin{array}{l}\text { Seq SS } \\
890,989\end{array}$} & \multicolumn{2}{|c|}{ Contribution } & Adj SS & \multirow{2}{*}{$\begin{array}{l}\text { Adj MS } \\
63,642\end{array}$} & \multirow{2}{*}{$\frac{\text { F-Value }}{12,06}$} & \multirow{2}{*}{$\frac{\text { P-Value }}{0,000}$} \\
\hline Model & & & & $91,84 \%$ & & 890,989 & & & \\
\hline Linear & & 4 & 799,385 & $82,40 \%$ & & 799,385 & 199,846 & 37,87 & 0,000 \\
\hline A & & 1 & 35,042 & $3,61 \%$ & & 35,042 & 35,042 & 6,64 & 0,021 \\
\hline B & & 1 & 113,535 & $11,70 \%$ & & 113,535 & 113,535 & 21,51 & 0,000 \\
\hline $\mathrm{C}$ & & 1 & 78,482 & $8,09 \%$ & & 78,482 & 78,482 & 14,87 & 0,002 \\
\hline $\mathrm{D}$ & & 1 & 572,327 & $58,99 \%$ & & 572,327 & 572,327 & 108,45 & 0,000 \\
\hline Square & & 4 & 49,766 & $5,13 \%$ & & 49,766 & 12,442 & 2,36 & 0,100 \\
\hline $\mathrm{A}^{*} \mathrm{~A}$ & & 1 & 0,249 & $0,03 \%$ & & 0,706 & 0,706 & 0,13 & 0,720 \\
\hline $\mathrm{B} * \mathrm{~B}$ & & 1 & 45,002 & $4,64 \%$ & & 38,543 & 38,543 & 7,30 & 0,016 \\
\hline $\mathrm{C} * \mathrm{C}$ & & 1 & 3,395 & $0,35 \%$ & & 3,900 & 3,900 & 0,74 & 0,404 \\
\hline$D * D$ & & 1 & 1,120 & $0,12 \%$ & & 1,120 & 1,120 & 0,21 & 0,652 \\
\hline 2-Way Interc & ction & 6 & 41,837 & $4,31 \%$ & & 41,837 & 6,973 & 1,32 & 0,307 \\
\hline$A * B$ & & 1 & 2,402 & $0,25 \%$ & & 2,403 & 2,403 & 0,46 & 0,510 \\
\hline$A^{*} \mathrm{C}$ & & 1 & 18,490 & $1,91 \%$ & & 18,490 & 18,490 & 3,50 & 0,081 \\
\hline$A * D$ & & 1 & 18,922 & $1,95 \%$ & & 18,922 & 18,922 & 3,59 & 0,078 \\
\hline $\mathrm{B} * \mathrm{C}$ & & 1 & 1,440 & $0,15 \%$ & & 1,440 & 1,440 & 0,27 & 0,609 \\
\hline$B * D$ & & 1 & 0,422 & $0,04 \%$ & & 0,422 & 0,422 & 0,08 & 0,781 \\
\hline$C^{*} \mathrm{D}$ & & 1 & 0,160 & $0,02 \%$ & & 0,160 & 0,160 & 0,03 & 0,864 \\
\hline Error & & 15 & 79,161 & $8,16 \%$ & & 79,161 & 5,277 & & \\
\hline Lack-of-Fit & & 10 & 78,686 & $8,11 \%$ & & 78,686 & 7,869 & 82,83 & 0,000 \\
\hline Pure Error & & 5 & 0,475 & $0,05 \%$ & & 0,475 & 0,095 & & \\
\hline Total & & 29 & 970,150 & 100,00 & & & & & \\
\hline $\mathbf{S}$ & R-sq & & -sq(adj) & PRESS & R-sq(pred) & AICc & BIC & & \\
\hline 2,29726 & $91,84 \%$ & & $4,22 \%$ & 453,914 & $53,21 \%$ & 188,09 & 168,66 & & \\
\hline
\end{tabular}

Table 5. Analysis of variance for tensile strength

\subsection{Influence of process parameters on tensile strength}

Fig. 5. shows the individual influence of each of the parameters on the tensile strength. It can be concluded that the most significant influence on the tensile strength have the wall thickness and infill density. For parts with an infill structure, the strength can significantly increase with increasing wall thickness. Also, increasing the infill density over $40 \%$ leads to a significant increase in strength. The print temperature and the layer thickness have a smaller influence on the tensile strength. Increasing the printing temperature to $230{ }^{\circ} \mathrm{C}$ also increases the tensile strength. The recommended printing temperature from the material manufacturer is around 200 degrees, but after these studies it can be concluded that better results, given the tensile strength, can be achieved at higher printing temperatures $\left(230^{\circ} \mathrm{C}\right)$.

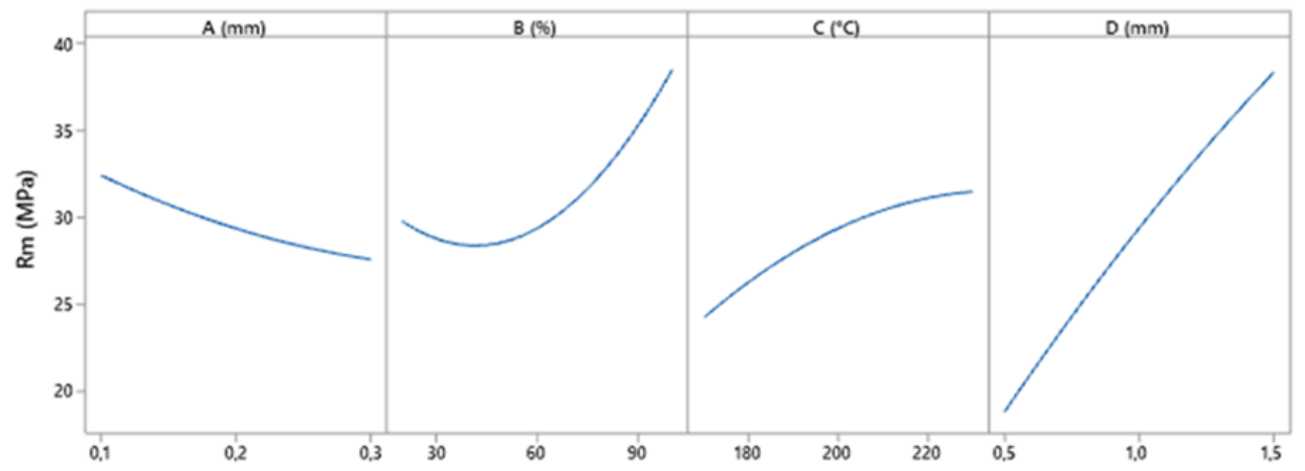

Fig. 5. Individual influence of the process parameters on the tensile strength 
The 3D surface plots between analyzed process parameter interactions for tensile strength is shown in Fig. 6(a-f). From Fig. 6(e) it can be observed that tensile strength of built parts increases with increasing infill density and wall thickness. This is because an increase in wall thickness shifts the stress concentracion zone from the outer edge surface to the middle of the specimen.

Tensile strength is directly affected by the layer thickness and decreases with increasing in layer thickness, especially at lower printing temperature, higher infill density and higher wall thickness (Fig. 6(a-c)). From Fig. 6.(b, d, f) it can be concluded that tensile strength increases with increasing printing temperature, under all printing conditions.
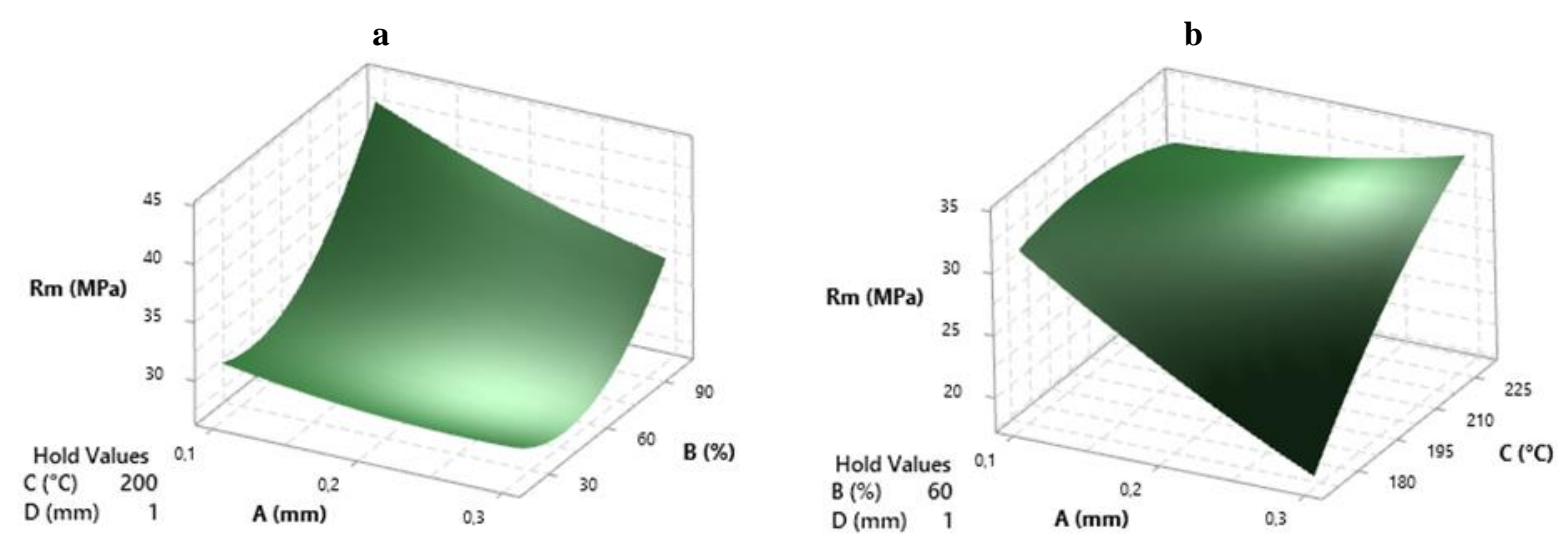

c
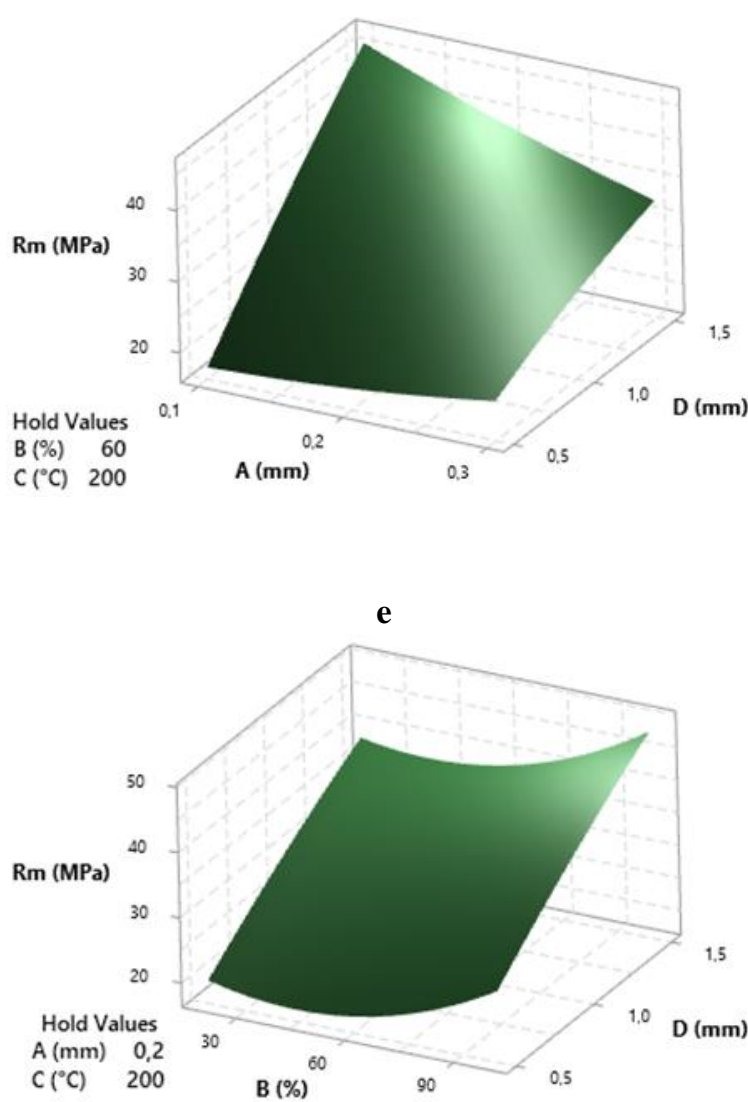

d

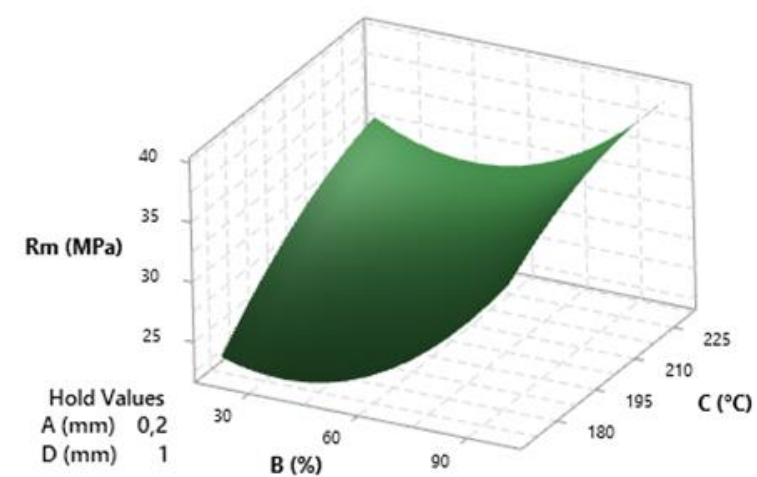

$\begin{array}{lr}A(\mathrm{~mm}) & 0,2 \\ D(\mathrm{~mm}) & 1\end{array}$

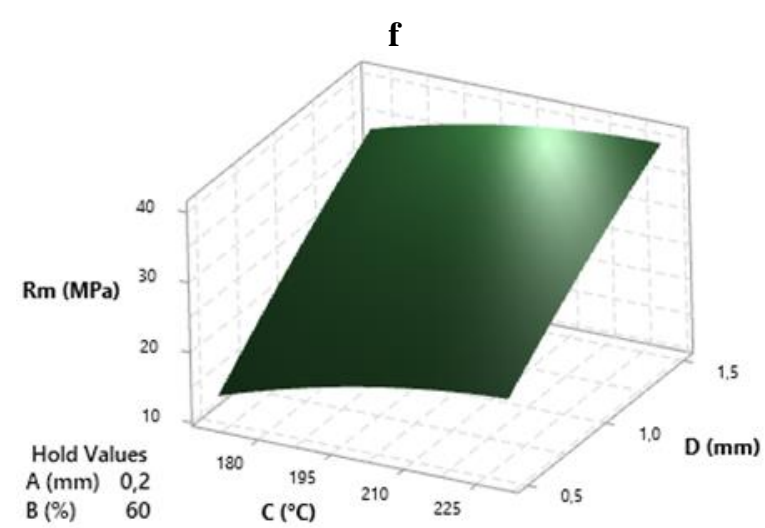

Fig. 6. 3D response surface plots representing various interactive effects of parameters on tensile strength 


\section{Conclusion}

This paper examines the influence of selected FDM process parameters (layer thickness, infill density, printing temperature and wall thickness) on the tensile strength of the built parts. Design of experiment for doing the experiments makes use of Circumscribed Central Composite Design (CCCD). Empirical relationship between response and different process parameters is established using RSM, and its validity is checked using ANOVA. The developed relationship between tensile strength (output) and process parameters (input) is able to explain the $91.84 \%$ of variability in the response. Effect of various factors and their interactions are explained using response surface plots.

It shown that the tensile strength is influenced significantly infill density and wall thickness; and less significantly printing temperature and layer thickness. In order to improve the tensile strength of FDM parts made of PLA materials, it is necessary to increase the infill density and wall thickness, decrease the layer thickness, and set the printing temperature in range $200-230{ }^{\circ} \mathrm{C}$. The future research is to investigate the effect of all analyzed parameters on tensile strength for different building directions.

\section{References}

[1] ASTM (2012) Standard terminology for additive manufacturing technologies. Standard F2792-12a, ASTM International. Available from International Organization for Standardization (ISO), 1, ch. De la Voie-Creuse, Case postale 56, CH-1211, Geneva 20, Switzerland

[2] Čekić, A.; Begić-Hajdarević, Đ.; Čohodar, M.; Muhamedagić, K. \& Osmanlić, M. (2019). Optimization of Stereolithography and Fused Deposition Modeling Process Parameters, Proceedings of the 30th DAAAM International Symposium, pp.0681-0687, B. Katalinic (Ed.), Published by DAAAM International, ISBN 978-3902734-22-8, ISSN 1726-9679, Vienna, Austria DOI: 10.2507/30th.daaam.proceedings.093

[3] Čekić, A.; Begić-Hajdarević, Đ.; Muhamedagić, K. \& Guzanović, N. (2018). Experimental Investigations of Process Parameters Influence on Dimensional Accuracy and Mechanical Properties of FDM Manufactured Parts, Proceedings of the 29th DAAAM International Symposium, pp.0210-0214, B. Katalinic (Ed.), Published by DAAAM International, ISBN 978-3-902734-20-4, ISSN 1726-9679, Vienna, Austria DOI: 10.2507/29th.daaam.proceedings.030

[4] Pandžić, A.; Hodžić, D. \& Milovanović, A. (2019). Effect of Infill Type and Density on Tensile Properties of PLA Material for FDM Process, Proceedings of the 30th DAAAM International Symposium, pp.0545-0554, B. Katalinic (Ed.), Published by DAAAM International, ISBN 978-3-902734- 22-8, ISSN 1726-9679, Vienna, Austria DOI: 10.2507/30th.daaam.proceedings.074

[5] Uzair, K. uz Zaman; Emilien, B.; Ali, S.; Mickael, R. \& Aamer Ahmed, B. (2018). Impact of fused deposition modeling (FDM) process parameters on strength of built parts using Taguchi's design of experiments, The International Journal of Advanced Manufacturing Technology, https://doi.org/10.1007/s00170-018-3014-6

[6] Harris, M.; Potgieter, J.; Archer, R. \& Mahmood Arif, K. (2019). Effect of Material and Process Specific Factors on the Strength of Printed Parts in Fused Filament Fabrication: A Review of Recent Developments, Materials 2019, 12, 1664; doi:10.3390/ma12101664

[7] Alafaghani, A.; Qattawi, A.; Alrawi, B. \& Guzman, A. (2017). Experimental Optimization of Fused Deposition Modelling Processing Parameters: a Design-for-Manufacturing Approach, Proceedings of 45th SME North American Manufacturing Research Conference, NAMRC 45, LA, USA, doi: 10.1016/j.promfg.2017.07.079

[8] Kohad, A. \& Dalu, R. (2010). Optimization of Process Parameters in Fused Deposition Modeling: A Review, International Journal of Innovative Research in Science, Engineering and Technology, Volume 6, Special Issue 1, January 2017, ISSN (Online) : 2319 - 8753, ISSN (Print) : 2347 - 6710

[9] Othman, F. M., Abbas, T. F. \& Ali, H. B. (2018). Influence of Process Parameters on Mechanical Properties and Printing Time of FDM PLA Printed Parts Using Design of Experiment, Dr. Farhad Mohammad Othman Journal of Engineering Research and Application, Vol. 8, Issue 7 (Part -II) July 2018, pp 65-69, ISSN : 2248-9622

[10] Govind, P. P. \& Parkhe, A. (2018). Parameters optimization of fused deposition modelling process for the improvement of tensile strength using Taguchi based grey relational analysis, International Journal of Advance Research, Ideas and Innovations in Technology, Vol. 4, Issue 5, ISSN: 2454-132X

[11] Douglas, C. Montgomery. (2012). Design and Analysis of Experiments, John Wiley \& Sons, Inc., Arizona State University, ISBN 978-1118-14692-7

[12] Mishra, S. B. \& Mahapatra, S. S. (2014). Improvement in Tensile Strength of FDM Built Parts by Parametric Control, Applied Mechanics and Materials Vols 592-594 (2014) pp 1075-1079, doi:10.4028/www.scientific.net/AMM.592-594.1075

[13] Anoop, K. Sood.; Raj., K. Ohdar \& Siba, S. Mahapatra (2011). Experimental investigation and empirical modelling of FDM process for compressive strength improvement, Journal of Advanced Research, Volume 3, Issue 1, January 2012, pp 81-90 